\title{
Spark plasma sintering of electro conductive nanocomposite $\mathrm{Al}_{2} \mathrm{O}_{3}-\mathrm{SiCw}-\mathrm{TiC}$
}

\author{
Sergey S. Pozhidaev, Anton E. Seleznev, Nestor W. Solis Pinargotea \\ AND PAVEL Yu. Peretyagin \\ Moscow State University of Technology "STANKIN", 1 Vadkovsky per., 127994 Moscow GSP-4, Russian Federation
}

Received 23 September 2015, Accepted 2 October 2015

\begin{abstract}
The method of production nanostructured ceramic $\mathrm{Al}_{2} \mathrm{O}_{3}-\mathrm{SiCw}-\mathrm{TiC}$ with high operational properties by spark plasma sintering is developed in this work. The obtained nanoceramic material was compared to $\mathrm{Al}_{2} \mathrm{O}_{3}-\mathrm{SiCw}$. The homogenous compound of initial nanostructured powders of different phases and sizes was made by the methods of colloid blending and spraying. The microstructure, hardness, fracture strength, phase's analysis, electro conductive properties of the samples were researched. The electro conductivity of sintered nanocomposite $\mathrm{Al}_{2} \mathrm{O}_{3}-\mathrm{SiCw}$-TiC enables to process it by electrical discharge machining.
\end{abstract}

Key words: Spark plasma sintering / nanomaterials / nanoceramics / nanocomposites / electro conductivity

\section{Introduction}

Advanced ceramic materials are widely used in various high-tech fields of industry, such as aerospace, transportation, power and mechanical engineering industries [1]. In most cases, high requirements are placed on ceramic products in terms of manufacturing precision, due to the need for their complex geometric shape [2]. Conventional mechanical processing of brittle and hard ceramic materials is very labor-consuming. Generally, expensive diamond grinding is used, which is characterized by low processing productivity and complexity in the processing of products with complex geometric shape, including miniaturized ones [3].

Electric discharge treatment is an effective alternative to conventional methods of mechanical processing of high hardness ceramic materials, however, processed materials must have the necessary electric conductivity. Earlier research in the field of electric discharge treatment of monophasic ceramics, ceramic composites, and cermet have shown that the availability of electric resistance of less than $1 \Omega . \mathrm{m}$ is required [4]. Ceramic materials with such values of electric resistance can be successfully processed using electric discharge, and further increase in electric conductivity properties makes ceramic materials more suited for this type of processing [5].

From technical and technological points of view on receiving and treating ceramic materials, aluminum oxide $\left(\mathrm{Al}_{2} \mathrm{O}_{3}\right)$ and composites on the basis of it hold much

\footnotetext{
a Corresponding author: wachosolis@gmail.com
}

promise for most highly technological applications. At present, various components on its basis with improved mechanical properties, including the so-called nanocomposites, have been developed [6]. Microstructure and mechanisms of improving the mechanical properties of ceramic composite successfully conform to the previously developed concept, however, basic physical and mechanical properties for structural and tool materials (hardness and crack resistance) are still mutually exclusive, and their combined improvement requires further study [7].

Currently, in the field of combined improvement of basic properties ceramic components based on aluminum oxide, reinforced with silicon carbide fibers $\mathrm{Al}_{2} \mathrm{O}_{3}-\mathrm{SiC}_{\mathrm{w}}$, which become increasingly widespread, stand out [8]. For instance, due to its unmatched cutting and physical and mechanical properties (hardness and crack resistance), this composite is widely used as cutting ceramics for the processing of tempered steel and heat resistant alloys.

To improve basic properties of $\mathrm{Al}_{2} \mathrm{O}_{3}-\mathrm{SiC}_{\mathrm{w}}$ composite, various technologies of sintering and preparation of powdered materials were used [1-4]. The main goal of the performed research is, on the one hand, to preserve the initial nanostructure of the material and, on the other hand, to ensure the even distribution of all phases, which have different density, particle size, and shape within the whole volume of the initial compact, which is complicated by van der Waals forces of intermolecular bonding and the presence of sinters in the powders with submicron particle size. It has been discovered that a combination of colloidal mixing and spark plasma sintering methods 
makes it possible to obtain a hard material with evenly distributed nanostructure, and, thus, to substantially improve physical and mechanical properties as compared to conventional technologies [4].

Colloidal (wet) mixing is the alternative to dry grinding. This method has been successfully used when obtaining nanopowder of oxides/oxides' compositions. In this case, the control over interparticle interaction forces [1-3] using DLFO (Deryagin-Landau-Ferway-Overbeck) theory includes getting a dispersed suspension and, as a final result, significantly decreases the heterogeneity of microstructure of a sintered composite. At the same time, various powders with different density have different deposition rates, with large density difference substantially inducing segregation processes. Nowadays, the knowledge in colloidal chemistry of oxide powders is being intensively developed, starting with Parks' breakthrough work etc. Today, more than a thousand publications are dedicated to the comparison of oxide ceramics to other compounds, the analysis of the systems with metal nanoparticles or carbide nanofibers [8]. Thus, the analysis as to the parameters of colloidal mixing process and subsequent drying, including the rheological behavior of mixed compositions of nanopowders of various phases and particle sizes, is currently open for fundamental research.

Spark plasma sintering (SPS) is an advanced and promising method of consolidating electrically conductive and non-conductive ceramic and metallic powders of various phases and particle sizes. The main point of the spark plasma sintering process is in simultaneous passage of electric current impulses through a compact and a graphite matrix with the application of coaxial pressure of up to $100 \mathrm{MPa}$. One of the factors of high hardness is nanostructure, which is preserved in samples due to the use of SPS; at the same time, high solidification rate of powder composition may be observed, high-quality and even size distribution of particles is achieved when using much lower temperatures as compared with other sintering methods. The main advantages of this technology are the preservation of the nanostructure of the initial composition, substantial decrease in the time spent on the process of sintering, and economic effectiveness when manufacturing high-volume products from nanocomposites.

At the same time, $\mathrm{Al}_{2} \mathrm{O}_{3}-\mathrm{SiC}_{\mathrm{w}}$ ceramic composite is an insulator, it is impossible to process by means of electric discharge, and the only possible way of processing is expensive and labor-consuming diamond grinding and cutting. This drawback considerably limits the sphere of use as to such ceramics and currently, only the products with simple geometric shape made of it are widespread now, such as accessory polyhedral cutting plates. The only possible solution to this problem is the inclusion of additional electrically conductive phase, for example, the third phase in the shape of a nanosized semi-conductor. These may be refractory metal nanoparticles, carbon nanotubes, or graphene [8], as well as ultradispersed particles of electrically conductive ceramics. Ultradispersed titanium carbide (TiC), which has high hardness and crack resistance properties, can be considered such electrically conductive ceramics.

The goal of this work is to obtain nanocomposite material based on aluminum oxide, which has increased hardness and crack resistance properties, as well as the electrical conductivity necessary for its processing using electric discharge.

\section{Materials and methods of the research}

For the preparation and sintering of powder composition using the SPS method, commercially obtainable nanoparticles and nanofibers have been chosen: (1) aluminum oxide $\left(\mathrm{Al}_{2} \mathrm{O}_{3}\right)$ manufactured by Taimei (Japan), with a particle size less than $500 \mathrm{~nm}$, spherical particle shape, density of $3.93 \pm 0.1$ g.cm ${ }^{-3}$; (2) silicon carbide fibers $\left(\mathrm{SiC}_{\mathrm{w}}\right)$ manufactured by Advanced Composite Materials (USA), with the fibers of cylindrical shape, with the diameter less than $500 \mathrm{~nm}$, and the side correlation of $1: 10$, the density of $3.25 \pm 0.1$ g.cm ${ }^{-3}$; (3) ultradispersed titanium carbide (TiC) manufactured by NanoAmor (USA), with the spherical particles having the size less than $50 \mathrm{~nm}$ and the density of $4.58 \pm 0.1 \mathrm{~g} . \mathrm{cm}^{-3}$.

At the first stage of preparing the suspension, initial powdered materials are mixed in a certain proportion with distilled water and Dolapix deflocculant manufactured by Zschimmer and Schwarz (Germany), to achieve the necessary degree of viscosity as to the suspension. The prepared suspension is processed in a spray drier. B-290 spray drier manufactured by BUCHI (Switzerland) was used in the experiment. During spray drying, all processing parameters (exhaustion rate, air flow rate) were maintained stable; only the temperature impact at the intake and the outlet was examined. The obtained granules were examined using a scanning electron microscope (SEM) in order to obtain spherical granules without silicon carbide fiber $\left(\mathrm{SiC}_{\mathrm{w}}\right)$ segregation.

Further on, $\mathrm{Al}_{2} \mathrm{O}_{3}-\mathrm{SiC}_{\mathrm{w}}-\mathrm{TiC}$ is mixed in ethanol in a ball grinder for $48 \mathrm{~h}$, grinded in an attritor for $4 \mathrm{~h}$, and then dried at $80{ }^{\circ} \mathrm{C}$, and sifted.

During the final stage, the sintering procedure of the experimental cylindrical sample with $40 \mathrm{~mm}$ diameter is performed using a hybrid SPS KCE FCT H-HP D 25-SD unit. Maximum temperature, heating rate, hold time, and applied pressure are the main input parameters which influence the end result. Rational values of these parameters were chosen based on the performed experimental research in order to achieve maximum density value, for which different pressure values and heating rates of samples were applied.

The density of the obtained nanocomposite has been determined using the method of hydrostatic weighing according to ASTM C373-88 standard. The method uses Archimedes' principle. Density of the sintered material is determined by the formula

$$
P=\left(1-\frac{\rho_{v}}{\rho_{t}}\right) 100 \%,
$$




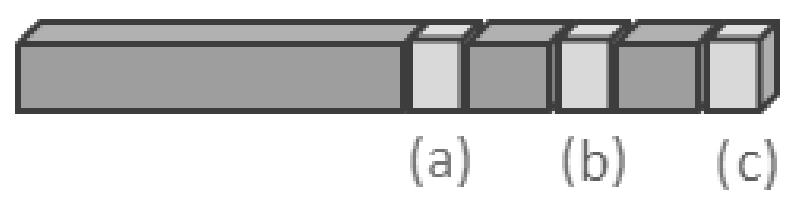

Fig. 1. Analysis of a profile according to the sample's radius from the center (a) to the edge (b).

where $\rho_{t}$ is the real density of the material expressed in g. $\mathrm{cm}^{-3}$;

$$
\rho_{v}=\frac{m}{V}
$$

where $m$ is the mass of the sample in $\mathrm{kg} ; V$ is the volume of the sample pores in $\mathrm{cm}^{3}$.

The microstructure of the nanocomposite and sinters of the nanopowder composition after spray drying has been analyzed using the method of scanning electronic microscopy on Quanta FEG 650, FEI (USA) SEM, equipped with the detectors of secondary and elastically reflected electrons.

Vickers' hardness $\left(H_{v}\right)$ has been determined using microindentation method, where the force of $1.96 \mathrm{~N}$ is applied to a polished surface (with roughness Ra up to 0.1 ) during $10 \mathrm{~s}$, and hardness value is determined according to the formula:

$$
H_{V}=1.854 \frac{P}{d^{2}}
$$

where $P$ is the applied force, $N ; d$ is the diagonal in $\mathrm{m}$.

Crack resistance $K_{\text {IC }}$ has also been determined using microindentation, by measuring the geometry of cracks obtained by indentation of the indenter for measuring Vickers' microhardness with the application of certain force (Image 4$). K_{\text {IC }}$ is measured according to the formula:

$$
K_{\text {IC }}=0.0752 \frac{P}{C^{3 / 2}}
$$

where $P$ is the applied force in $N ; C$ - size of a crack appearing from the top of the imprint in $\mathrm{m}$.

Hardness and crack resistance of the obtained nanocomposite have been measured in three different areas of the cross section of the sintered material, from the periphery to the center, in order to determine the anisotropy of mechanical properties caused by possible temperature gradients during SPS sintering (Fig. 1).

Phase analysis has been performed on Empyrean X-ray diffractometer ( $P A N$ alytical, t he Netherlands). Initial samples, their composition, and the samples, sintered using SPS have been analyzed.

The electrical resistance of the $\mathrm{Al}_{2} \mathrm{O}_{3}-\mathrm{SiC}_{\mathrm{w}}-\mathrm{TiC}$ nanocomposite has been measured using four-wire connection with a separate power source and dual-channel nanovoltmeter, according to ASTM C611 standard.

\section{Results and discussion}

As a preliminary measure, to determine the maximum ratios of each component of the ceramic composite, the analysis of each component's rheological behavior has been performed in distilled water with the addition of special Dolapix deflocculant, in order to obtain the degree of viscosity of the solution necessary for spray drying.

The following sustainable composition of the suspension has been defined: $36 \%$ of the hard substance (mixture of three components of $\mathrm{Al}_{2} \mathrm{O}_{3}-\mathrm{SiC}_{\mathrm{w}}$ - TiC with $42-36-22 \%$ ratio accordingly); $0.58 \%$ of Dolapix deflocculant, $<64 \%$ of distilled water. With this composition, the suspension viscosity amounts to $406.2 \mathrm{MPa}$, which is suitable for the performance of subsequent spray drying. To obtain granules during drying, $0.5 \%$ of bonding substance has been previously added into the suspension.

During the experiment on spray drying, the obtained agglomerates of nanoparticle composition were analyzed on SEM, at the same time, the analysis was performed with regard to different temperatures of air flow at the intake of the spray drier, ranging from $110^{\circ} \mathrm{C}$ to $160{ }^{\circ} \mathrm{C}$, respectively (Figs. 2a-2c). The micro photos of nanoparticle agglomerates show various defects in granules, such as the irregular shape or $\mathrm{SiC}_{\mathrm{w}}$ segregation. Therefore, it became necessary to increase the contents of the hard component up to $40 \%$, and that of the bonding substance - up to $1 \%$.

The nanoparticle agglomerates with optimized contents obtained with different air flow temperatures at the spray drier intake are shown in Figures $2 \mathrm{~d}-2 \mathrm{f}$.

After the modification of suspension composition, spherical granules without $\mathrm{SiC}_{\mathrm{w}}$ segregation can be seen. Apart from that, correlation between granule size and temperature at the spray drier intake has been found. Larger granules were obtained, when the temperature at the intake was increased. With the temperature of $160{ }^{\circ} \mathrm{C}$ at the intake, an average granule size is $17 \pm 15 \mu \mathrm{m}$.

After the performance of all additional operations on powder material preparation, the acquired compact was sintered using spark plasma sintering. The operating cycle of a $40 \mathrm{~mm}$ - diameter cylindrical test sample sintering process on a hybrid KCE FCT H-HP D 25-SD SPS unit was analyzed in order to determine maximum density value, for that purpose various values of pressure and heating rate of the sample were used. The sustainable technological modes of SPS sintering of the $\mathrm{Al}_{2} \mathrm{O}_{3}-\mathrm{SiC}_{\mathrm{w}}{ }^{-}$ $\mathrm{TiC}$ nanocomposite are shown in Table 1 , which ensure obtaining the material with the density that is more than $99 \%$ as compared to the theoretical level.

The microstructure of a sintered ceramic nanocomposite after the respective metallographic sample preparation has been analyzed using a SEM (Fig. 3). On the image received, it is clearly seen that, due to the lengthy mixing process of the powder material, all phases of the obtained structure (dark area - TiC, grey area - $\mathrm{SiC}_{\mathrm{w}}$, light area $\mathrm{Al}_{2} \mathrm{O}_{3}$ ) are evenly distributed within the whole volume of the sample. The initial nanostructure with regard to the initial powders has been preserved.

The results of hardness, density, and crack resistance measurements are set forth in Table 2. As can be seen from Table 2, the hardness and density values are not changed within the whole volume of the sample. Such 


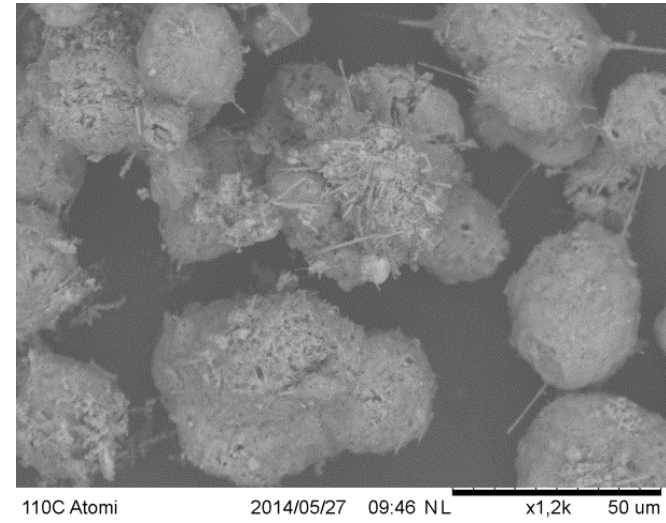

(a)

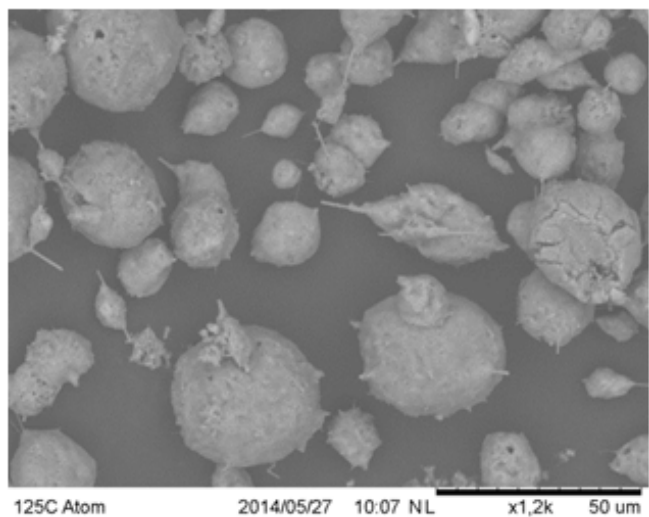

(b)

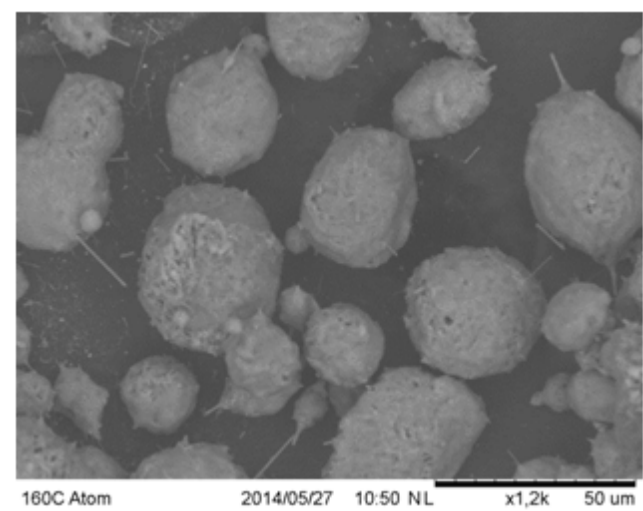

(c)

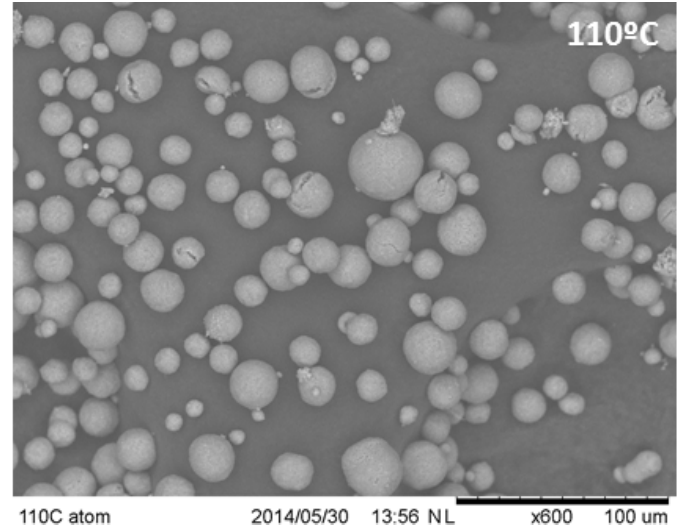

(d)

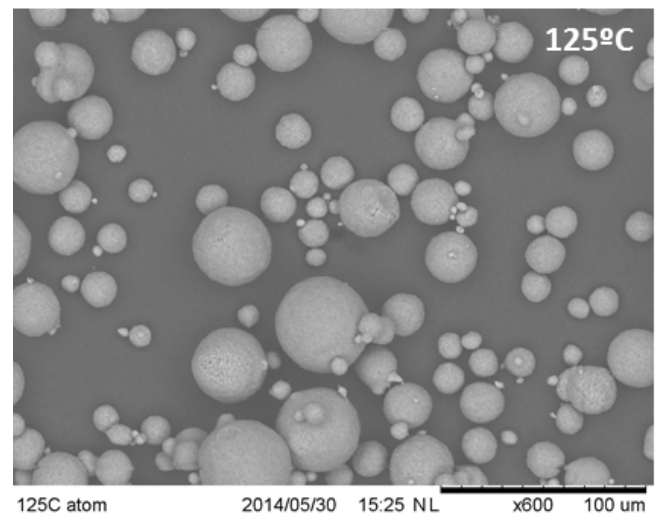

(e)

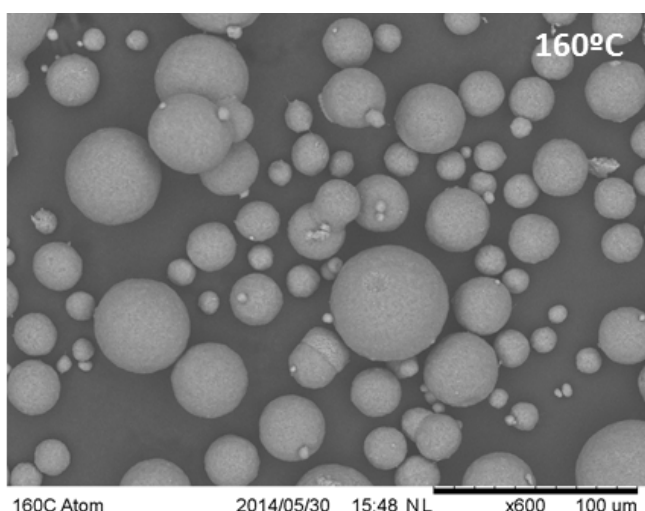

(f)

Fig. 2. Granules of $\mathrm{Al}_{2} \mathrm{O}_{3}$-SiCw-TiC nanocomposite ( $36 \%$ of hard substance, $0.58 \%$ of deflocculant, $0.5 \%$ of bonding substance) after spray drying at: (a) $110{ }^{\circ} \mathrm{C}$; (b) $125^{\circ} \mathrm{C}$; (c) $160{ }^{\circ} \mathrm{C}$ and a composition of $40 \%$ of the hard substance, $1.0 \%$ of the deflocculant, $1 \%$ of bonding substance at (d) $110{ }^{\circ} \mathrm{C}$; (e) $125^{\circ} \mathrm{C}$; (f) $160{ }^{\circ} \mathrm{C}$.

Table 1. Sustainable parameters of SPS sintering of the $\mathrm{Al}_{2} \mathrm{O}_{3}-\mathrm{SiCw}-\mathrm{TiC}$ nanocomposite.

\begin{tabular}{cccc}
\hline $\begin{array}{c}\text { Maximum temperature } \\
\left({ }^{\circ} \mathrm{C}\right)\end{array}$ & $\begin{array}{c}\text { Heating rate } \\
\left({ }^{\circ} \mathrm{C} \cdot \mathrm{min}^{-1}\right)\end{array}$ & $\begin{array}{c}\text { Hold time } \\
(\min )\end{array}$ & $\begin{array}{c}\text { Maximum pressure } \\
(\mathrm{MPa})\end{array}$ \\
\hline 1780 & 100 & 5 & 40 \\
\hline
\end{tabular}




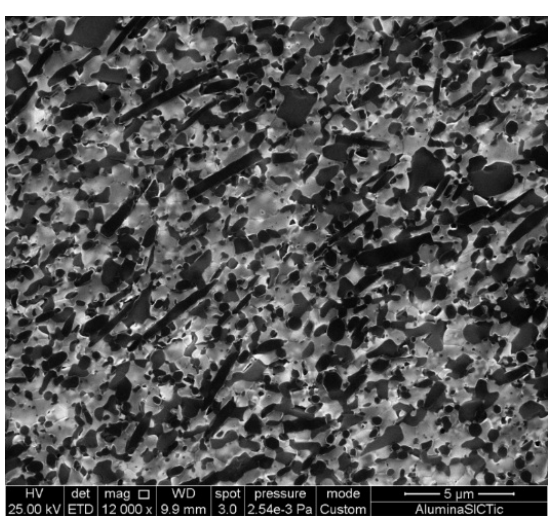

(a)

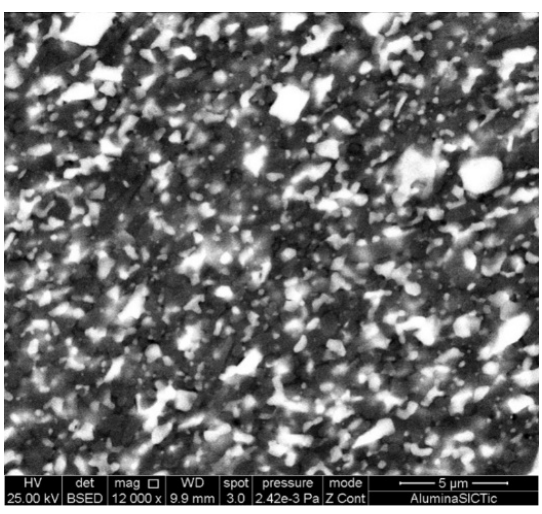

(b)

Fig. 3. SEM-image of a microstructure of the same area of the sintered $\mathrm{Al}_{2} \mathrm{O}_{3}-\mathrm{SiCw}-\mathrm{TiC}$ nanocomposite material: (a) - in secondary electrons; (b) - in elastically reflected electrons.

Table 2. Results of density, hardness and crack resistance measurements of the obtained $\mathrm{Al}_{2} \mathrm{O}_{3}-\mathrm{SiCw}$-TiC nanocomposite in three different areas of the sample (according to Fig. 1).

\begin{tabular}{cccccc}
\hline No. & $\begin{array}{c}\text { Periphery radius } \\
\text { of the profile }\end{array}$ & $\begin{array}{c}\text { Density } \\
\text { (\% from theoretical) }\end{array}$ & $\begin{array}{c}\text { Internal hardness } \\
(\mathrm{GPa})\end{array}$ & $\begin{array}{c}\text { Surface hardness } \\
(\mathrm{GPa})\end{array}$ & $\begin{array}{c}\text { Crack resistance } \\
\mathrm{K}_{1 \mathrm{C}}, \mathrm{MPa}_{\mathrm{m}}{ }^{1 / 2}\end{array}$ \\
\hline 1 & $\mathrm{a}$ & $>99 \%$ & $22.19 \pm 0.75$ & $22.18 \pm 0.54$ & $6.5 \pm 0.1$ \\
2 & $\mathrm{~b}$ & $>99 \%$ & $22.74 \pm 0.95$ & $22.61 \pm 0.60$ & $6.5 \pm 0.1$ \\
3 & $\mathrm{c}$ & $>99 \%$ & $23.32 \pm 1.04$ & $23.07 \pm 1.09$ & $6.4 \pm 0.1$ \\
\hline
\end{tabular}

homogeneity is achieved due to the even heat distribution within the sample during spark plasma sintering.

Measuring results have shown that Vickers' hardness has increased by approximately $17 \%$ as compared to the $\mathrm{Al}_{2} \mathrm{O}_{3}-\mathrm{SiC}_{\mathrm{w}}$-TiC composite obtained by hot pressing [9]. Such result is achieved due to a smaller particle size retained after sintering, while the crack resistance of $\mathrm{Al}_{2} \mathrm{O}_{3}$ $\mathrm{SiCw}-\mathrm{TiC}$ material is by $23 \%$ higher than $\mathrm{Al}_{2} \mathrm{O}_{3}-\mathrm{SiC}_{\mathrm{w}}$ obtained by hot isostatic pressing.

The X-ray analysis performed has shown that the prepared powder composition contains only $\mathrm{Al}_{2} \mathrm{O}_{3}, \alpha-\mathrm{SiC}$ and $\mathrm{TiC}$ phases, and the sintered sample shows a small peak at $\theta=30.9^{\circ}$ area, which can be related to graphite used in the matrix during sintering.

The measurements as to the electric resistance of the obtained ceramic nanocomposite have shown the values, which are considerably lower than maximum allowable electric resistance for EDM processing. Electric resistance value is $\rho=3.15 \times 10^{-5} \pm 0.1 \times 10^{-5} \Omega . \mathrm{m}$ (5), which is considerably lower than the maximum allowable resistance of $1 \Omega . \mathrm{m}$

\section{Conclusion}

New technology of obtaining a nanostructured $\mathrm{Al}_{2} \mathrm{O}_{3}-$ $\mathrm{SiC}_{\mathrm{w}}-\mathrm{TiC}$ composite using spark plasma sintering method has been developed. The combination of advanced methods of ultradispersed nanopowders composition preparation of various phases, forms and particle sizes (colloidal mixing and spray drying) and hybrid spark plasma sintering have contributed to the concurrent increase in basic properties (hardness and crack resistance) of constructing materials and electric conductivity that makes it possible to perform electric discharge machining of the composite.

Even the distribution of all phases within the whole volume of the sintered composite has been achieved, whereas the analysis of the properties in various areas of the material has shown the absence of any anisotropy of mechanical properties. The measured density value amounts to $23 \pm 0.5 \mathrm{GPa}$, and the crack resistance value $\left(K_{1 \mathrm{C}}\right)-6.5 \pm 0.1 \mathrm{MPa} . \mathrm{m}^{1 / 2}$.

In order to summarize the attained results, one might state that a new class of constructing ceramic materials with the improved properties and electric conductivity $\left(\rho=3.15 \times 10^{-5} \pm 0.1 \times 10^{-5} \Omega . \mathrm{m}\right)$ for electric discharge machining has been obtained. Thus, the obtained nanocomposite material can greatly expand the limits as to the use of construction ceramics in modern high-tech industries, especially in those applications, where products of complex geometric shapes are needed, including the miniaturized ones, and that greatly improves their quality and reliability.

Acknowledgements. The work was performed within the framework of the Resolution of the Government of the Russian Federation dated 9 April 2010 No.220 "On measures taken to attract key scientists to Russian educational institutions of higher professional education and scientific establishments of state academies of science and state research centers of the Russian Federation" (Agreement No. 14.B25.31.0012 dated 26 June 2013). 


\section{References}

[1] L. Esteban-Tejeda, B. Cabal, F. Malpartida, R. LopezPiriz, R. Torrecillas, E. Saiz, A.P. Tomsia, J.S. Moya, Soda-lime glass-coating containing silver nanoparticles on Ti-6Al-4V alloy, J. Eur. Ceramic Soc. 32 (2012) 27232729

[2] L. Esteban-Tejeda, L.A. Diaz, C. Prado, B. Cabal, R. Torrecillas, J.S. Moya, Calcium and Zinc Containing Bactericidal Glass Coatings for Biomedical Metallic Substrates, Int. J. Molecular Sci. 15 (2014) 13030-13044

[3] A. Centeno, V.G. Rocha, B. Alonso, A. Fernández, C.F. Gutierrez-Gonzalez, R. Torrecillas, A. Zurutuza, Graphene for tough and electroconductive alumina ceramics, J. Eur. Ceramic Soc. 33 (2013) 3201-3210

[4] L.A. Diaz, M.A. Montes-Moran, P.Y. Peretyagin, Y.G. Vladimirov, A. Okunkova, J.S. Moya, R. Torrecillas, Zirconia-alumina-nanodiamond composites with gemological properties, J. Nanoparticle Res. 16 (2014) 1-9

[5] A.S. Vereschaka, S.N. Grigoriev, E.S. Sotova, A.A. Vereschaka, Improving the Efficiency of the Cutting Tools Made of Mixed Ceramics by Applying Modifying Nanoscale Multilayered Coatings, Adv. Mater. Res. 712 (2013) 391-394
[6] A.B. Nadykto, F. Yu, M.V. Jakovleva, J. Herb, Y. Xu, Amines in the Earth's atmosphere: a density functional theory study of the thermochemistry of pre-nucleation clusters, Entropy 13 (2011) 554-569

[7] V.V. Molodtsov, A.A. Okunkova, P.Y. Peretyagin, Manufacture of graphite electrodes for the electrospark machining of complex high-precision components, Russian Eng. Res. 32 (2012) 550-552

[8] A. Fernández, P. Peretyagin, W. Solis, R. Torrecillas, A. Borrell, Functionalization of carbon nanofibres obtained by floating catalyst method, J. Nanomater. (2015) Art. no. 395014 .

[9] M. Suarez, A. Fernandez, J.L. Menendez, R. Torrecillas, H.U. Kessel, J. Hennicke, R. Kirchner, T. Kessel, Challenges and Opportunities for Spark Plasma Sintering: A Key Technology for a New Generation of Materials, Sintering Applications, Dr. Burcu Ertug (Ed.), 2013, ISBN: 978-953-51-0974-7, InTech, DOI: $10.5772 / 53706$ 